\section{Intravenous lidocaine does not attenuate the haemodynamic response of children to laryngoscopy and tracheal intubation}

William M. Splinter MD FRCP
The haemodynamic responses to laryngoscopy and intubation after induction of anaesthesia with thiopentone alone or in combination with $1.5 \mathrm{mg} \cdot \mathrm{kg}^{-1} \mathrm{IV}$ lidocaine were measured in 125 children age 2 to 12 yr to determine whether lidocaine administered one, two, three or four minutes before tracheal intubation attenuated the pressor response. Lidocaine did not attenuate the increases in heart rate and arterial blood pressure. The pressor response was significantly affected by baseline haemodynamic values, $P<0.05$. The increases in systolic and mean blood pressure were significantly affected by the age of the patient, $P<0.05$. Lidocaine is not a beneficial adjunct to induction of anaesthesia with thiopentone in healthy children for the purpose of attenuating the pressor response to intubation.

Les réponses hémodynamiques à la laryngoscopie et l'intubation après induction de l'anesthésie avec du thiopentone seul ou en combinaison avec $1.5 \mathrm{mg} \cdot \mathrm{kg}^{-1} \mathrm{~N}$ de lidocaine furent mesurées chez 125 enfants âgés de 2 à 12 ans afin de déterminer si la lidocaïne administrée un, deux, trois ou quatre minutes avant l'intubation trachéale atténue la réponse vasopressive. La lidocaïne n'a pas atténué l'augmentation de la fréquence

\section{Key words}

AGE FACTORS, ANAESTHESIA: paediatric;

ANAESTHETICS, INTRA VENOUS: lidocaine; COMPLICATIONS: hypertension;

INTUBATION, TRACHEAL: cardiovascular responses.

From the Department of Anaesthesia, Children's Hospital of Eastern Ontario, University of Ottawa, Ottawa, Ontario, Canada.

Presented, in part, at the IARS 64th Congress, Honolulu, Hawaii, March, 1990.

Address correspondence to: Dr. W. Splinter, Department of Anaesthesia, Children's Hospital of Eastern Ontario, 401 Smyth Road, Ottawa, Ontario, K1H 8LI. cardiaque et de la pression artérielle. La réponse vasopressive était significativement affectée par les valeurs hémodynamiques de base, $P<0.05$. L'augmentation de la pression artérielle systolique et de la pression artérielle moyenne était significa. tivement affectée par l'âge du patient, $P<0.05$. La lidocaïne n'est pas bénéfique lors de l'induction de l'anesthésie an thiopentone chez des enfants en bonne santé pour atténuer la réponse vasopressive de l'intubation

The sympathetic response to laryngoscopy and tracheal intubation and its pharmacological modification has been well documented. ${ }^{1-3} \mathrm{Most}$, if not all, of the investigations of the pressor response have involved adults. Children are also at risk of developing complications, such as cerebral vascular accidents and cardiac dysrhythmias, secondary to an excessive sympathetic response.

Previous investigations of healthy adults demonstrated that intravenous lidocaine decreased the haemodynamic responses during induction of anaesthesia, but this beneficial effect was only observed if lidocaine was administered three minutes before laryngoscopy.'

We sought to determine first whether $1.5 \mathrm{mg} \cdot \mathrm{kg}^{-1} \mathrm{IV}$ lidocaine attenuates the pressor response of children, and second the optimal time to administer lidocaine before laryngoscopy and tracheal intubation.

\section{Methods}

After hospital ethics committee and departmental approval, 125 elective, ASA physical status I-II surgical patients age 2 to $12 \mathrm{yr}$ were randomly assigned to one of five groups. (The blocked randomization with a block size of 125 was computer-generated.) Children were excluded for several factors, including previous treatment with sympatholytic drugs, an active seizure disorder, gastroesophageal reflux, and renal or hepatic dysfunction. Those children expected to have a difficult airway were also excluded. Informed, parental consent was obtained. 


\section{Baseline haemodynamic measurements}

On arrival in the operating room the patient's heart rate (HR), systolic blood pressure (SBP), mean blood pressure (MBP), and diastolic blood pressure (DBP) were monitored with a Dinamapp ${ }^{\circledR}$ automatic non-invasive blood pressure (NIBP) monitor. The average of the first two values, which were obtained one minute apart, constituted the baseline value.

\section{Induction of anaesthesia}

After breathing a mixture of 70 per cent $\mathrm{N}_{2} \mathrm{O}$ and 30 per cent $\mathrm{O}_{2}$ for one minute, an intravenous catheter was inserted, as is our practice. Thereafter, the $\mathrm{N}_{2} \mathrm{O}$ was discontinued and 100 per cent $\mathrm{O}_{2}$ was given for the remaining four minutes of the induction period. During induction the patients' haemodynamic variables were monitored every minute with the NIBP unit. The final values were obtained two minutes after tracheal intubation. Four groups of 25 patients were administered 1.5 $\mathrm{mg} \cdot \mathrm{kg}^{-1}$ lidocaine IV either one, two, three, or four minutes before laryngoscopy and intubation.

The remaining 25 patients were in the control group and did not receive lidocaine. Vecuronium $\left(0.08 \mathrm{mg} \cdot \mathrm{kg}^{-1}\right)$ and thiopentone $\left(6 \mathrm{mg} \cdot \mathrm{kg}^{-1}\right)$ were administered 1.9 minutes and 1.7 minutes before intubation, respectively, to all patients.

Tracheal intubation was performed within a 15 -sec period by a senior anaesthesia resident or a staff anaesthetist. After intubation, anaesthesia was maintained for the next two minutes with 70 per cent $\mathrm{N}_{2} \mathrm{O}, 30$ per cent $\mathrm{O}_{2}$ and 1.5 per cent halothane delivered through a coaxial circuit and controlled ventilation was established to maintain normocapnia. Patients were not stimulated during the observation period (from the start of induction to two minutes after intubation).

\section{Statistical analysis}

Demographic data were compared using ANOVA and Kruskal-Wallis Rank test where appropriate. Withingroup haemodynamic values were compared using repeated-measures ANOVA. Between-group compari-

TABLE I Patient characteristics (mean \pm SEM)

\begin{tabular}{llllll}
\hline Group * & $\begin{array}{l}\text { No. of } \\
\text { patients }\end{array}$ & $\begin{array}{l}\text { Age } \\
y r\end{array}$ & $\begin{array}{l}\text { Weight } \\
\mathrm{kg}\end{array}$ & $\begin{array}{l}\text { Baseline } \\
H R \min ^{-1}\end{array}$ & $\begin{array}{l}\text { Baseline } \\
\text { SBP mmHg }\end{array}$ \\
\hline I & 25 & $7.2 \pm 0.6$ & $25 \pm 2$ & $96 \pm 4$ & $117 \pm 2$ \\
II & 25 & $6.0 \pm 1.8$ & $21 \pm 1$ & $108 \pm 5$ & $120 \pm 4$ \\
III & 25 & $5.7 \pm 0.5$ & $24 \pm 3$ & $104 \pm 3$ & $116 \pm 3$ \\
IV & 25 & $6.1 \pm 0.9$ & $22 \pm 2$ & $96 \pm 3$ & $114 \pm 2$ \\
V & 25 & $6.5 \pm 0.5$ & $23 \pm 2$ & $107 \pm 5$ & $121 \pm 2$ \\
\hline
\end{tabular}

"Lidocaine, $1.5 \mathrm{mg} \cdot \mathrm{kg}^{-1}$, was administered to groups I, II, III and IV exactly $1,2,3$ and 4 minures before laryngoscopy, respectively.
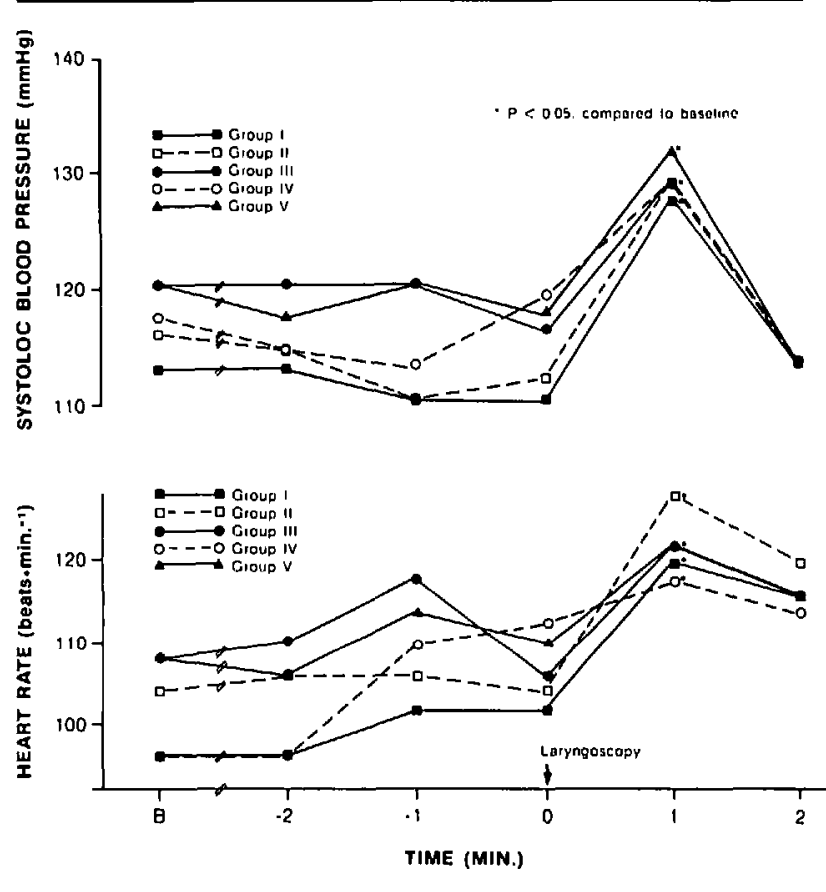

FIGURE The heart rate and systolic blood pressure at rest (time $=\mathrm{B}$; operating room baseline), during induction of anaesthesia, and before and after trachael intubation in patients treated with thiopentone only (Group $V$ ), and in combination with lidocaine one, two, three and four minutes before laryngoscopy, Groups I-IV, respectively

sons of the immediate post-intubation haemodynamic values were performed using ANCOVA (baseline variables and age were the covariates). Results were accepted as significant if $P<0.05$. Sample size was determined for beta $=0.2$, alpha $=0.05 / 5$ and a standardized difference of one.

\section{Results}

There were no significant differences between the groups' weight, age, gender and ASA physical status (Table I).

Lidocaine treatment did not alter the induction pressor response (Figure). Haemodynamic responses to laryngoscopy were significantly different from baseline values (repeated-measures ANOVA), and had peaked by one minute after tracheal intubation. By two minutes after intubation all the values had returned to baseline. Between-group comparisons of the one minute postintubation HR, SBP, DBP and MBP did not identify any significant differences among the groups (ANCOVA, $P$ $<0.05$ ).

The pressor response to laryngoscopy and intubation was not altered by treatment with lidocaine, but it increased with patient age, baseline $H R$, and baseline SBP (ANCOVA $P<0.05$ ). The pressor response increased by $3.2 \pm 0.7 \mathrm{bpm}$ for every $10 \mathrm{bpm}$ rise in baseline $\mathrm{HR}$, by $2.8 \pm 0.9 \mathrm{mmHg}$ for each $10 \mathrm{mmHg}$ 
TABLE II Increase in haemodynamic variables (mean \pm SEM) (one minute post-intubation value less baseline value)

\begin{tabular}{llrrr}
\hline \multicolumn{5}{l}{ Variable* $^{*}$} \\
\cline { 2 - 5 } Group & \multicolumn{1}{l}{ HR } & \multicolumn{1}{l}{$S B P$} & \multicolumn{1}{c}{$D B P$} & \multicolumn{1}{c}{$M B P$} \\
\hline I & $21 \pm 3$ & $12 \pm 2$ & $14 \pm 3$ & $12 \pm 3$ \\
II & $13 \pm 4$ & $9 \pm 4$ & $9 \pm 4$ & $9 \pm 5$ \\
III & $23 \pm 4$ & $13 \pm 4$ & $9 \pm 4$ & $14 \pm 4$ \\
IV & $24 \pm 3$ & $13 \pm 3$ & $11 \pm 3$ & $12 \pm 2$ \\
V & $14 \pm 4$ & $11 \pm 3$ & $10 \pm 4$ & $13 \pm 4$ \\
\hline
\end{tabular}

"HR = heart rate, $\min ^{-1} ; \mathrm{SBP}, \mathrm{DBP}, \mathrm{MBP}=$ systolic, diastolic, mean blood pressure, respectively, mmHg.

incremental increase in baseline SBP, and by $1.3 \mathrm{mmHg}$ (SBP) for each $1 \mathrm{yr}$ increase in age. (Values are listed as mean $\pm \mathrm{SD}$.)

The average increase in HR and SBP from baseline values in response to laryngoscopy and intubation ranged from 13.5 to 24.3 beats $\cdot \mathrm{min}^{-1}$ and 8.9 to $13.4 \mathrm{mmHg}$, respectively (Table II).

\section{Discussion}

Haemodynamic stability during induction is a major objective in anaesthesia. There have been numerous pharmacological approaches: lidocaine, ${ }^{1-3}$ narcotics, ${ }^{4}$ deep anaesthesia with barbiturates or inhalational agents, vasodilators, ${ }^{5}$ and beta blockers ${ }^{6}$ have been used to modify the pressor response of adults.

The results of studies on the effect of lidocaine on induction haemodynamic variables have varied. ${ }^{1-3,7} \mathrm{Li}$ docaine may alter the response to laryngoscopy and intubation by decreasing MAC. (Lidocaine decreases MAC by 10 to 28 per cent ${ }^{8,9}$ ) In young adults the optimal time to administer IV lidocaine before intubation is approximately three minutes.' Lidocaine given one, two and five minutes before intubation had no beneficial effect.' This study was unable to demonstrate a significant effect of lidocaine on induction haemodynamic values if given one, two, three or four minutes before tracheal intubation. The lack of demonstratable benefit from intravenous lidocaine on the variables studied was unexpected. Theoretically, lidocaine should decrease MAC and obtund the laryngeal reflexes of children and thus attenuate the pressor response. The lack of improved control of haemodynamic variables during induction of anaesthesia may reflect a minimal effect of lidocaine on the anaesthetic requirements of children.

The pressor response of the children investigated in this study was less than expected. The observed average increase of $H R$ was 19 beats $\cdot \mathrm{min}^{-1}$ and the average SBP increase was $12 \mathrm{mmHg}$. This pressor response is less than that observed in adults. This may be secondary to "high" baseline values. The baseline value used in this investigation was the average of the first two values obtained in the operating room. Children are often quite stressed at this time increasing their haemodynamic values. Premedication with narcotics and/or benzodiazepines may decrease the stress present on arrival in the operating room, but it is not commonly administered to children and it may also modify the pressor response.

The pharmacological modification of the pressor response to laryngoscopy has been studied on numerous occasions. The statistical analysis of the data and which data is analyzed varies. This study compared postintubation haemodynamic variables using ANCOVA. This form of analysis determines whether differences among results occurred because of random error, treatment or other variables (covariates). Thus, ANCOVA does not ignore the effect of covariates, i.e., baseline haemodynamic value and subject's age when it analyzes for differences among groups due to treatment, i.e., lidocaine. Not only do the average blood pressure and HR vary with age, but we were able to demonstrate that the haemodynamic response (MBP and SBP) was significantly altered by the age of the subjects studied. In addition, like adults, a child with an elevated blood pressure would be expected to have a greater pressor response than a normotensive patient.

In summary, $1.5 \mathrm{mg} \cdot \mathrm{kg}^{-1}$ lidocaine given one, two, three or four minutes before laryngoscopy did not attenuate the pressor response to laryngoscopy and intubation of children.

\section{Acknowledgements}

The author thanks his colleagues in the Departments of Anaesthesia and Surgery for their guidance and cooperation; and Drs. Gary Johnson and Elliot Rhine for their helpful comments.

\section{References}

1 Tam S, Chung, F, Campbell M. Intravenous lidocaine: optimal time of injection before tracheal intubation. Anesth Analg 1987; 66: 1036-8.

2 Stoelting RK. Circulatory changes during direct laryngoscopy and tracheal intubation: influence of duration of laryngoscopy with or without prior lidocaine. Anesthesiology 1977; 47: 381-4.

3 Abou-Madi MN, Keszler H, Yacoub JM. Cardiovascular reactions to laryngoscopy and tracheal intubation following small and large intravenous doses of lidocaine. Can Anaesth Soc J 1977; 24: 12-9.

4 Kay $B$, Nolan D. Mayall R. Healy TEJ. The effect of sufentanil on the cardiovascular responses to tracheal intubation. Anaesthesia 1987; 42: 382-6. 
5 Kamra S, Wig J, Sapru RP. Topical nitroglycerin a safeguard against pressor responses to trachael intubation. Anaesthesia 1986; 41: 1087-91.

6 Cucchiara RF, Benefiel DJ, Matteo RS, DeWood M, Albin $M S$. Evaluation of esmolol in controlling increases in heart rate and blood pressure during endotracheal intubation in patients undergoing carotid endarterectomy. Anesthesiology 1986; 65: 528-31.

7 Chraemmer-Jorgensen B, Hoilund-Carlsen PF, Marving J, Christensen V. Lack of effect of intravenous lidocaine on hemodynamic responses to rapid sequence induction of general anesthesia. A double-blind controlled clinical trial. Anesth Analg 1986; 65: 1037-41.

8 Himes $R S$, Difazio CA, Burney RG. Effect of lidocaine on the anesthetic requirements for nitrous oxide and halothane. Anesthesiology 1977; 47: 437-40.

9 Phillips $O C$, Lyons WB, Harris LC, Nelson AT, Graff TD. Frazier $T M$. Intravenous lidocaine as an adjunct to general anaesthesia: a clinical evaluation. Anesth Analg 1960; 39: 317-22. 